\title{
Bioaccessibility of Arsenic in Mine Waste Contaminated Soils: a Case Study from an Abandoned Arsenic Mine in SW England (UK)
}

\author{
Barbara Palumbo-Roe* and Ben Klinck \\ British Geological Survey, Keyworth, Nottingham, NG12 5GG, UK
}

\section{ABSTRACT}

This study characterises the total As concentrations and As bioaccessibility in 109 soils from Devon Great Consols Mine, an abandoned Cu-As mine in Devon, SW England, UK and discusses the soil and mineralogical factors that influence the bioaccessibility of this element. These data provide the basis for developing more accurate exposure estimates for use in human health risk assessments. The median value of the percent bioaccesible As of $15 \%$ for these As rich soils contaminated by mining activities indicated that relatively little of the total As is present in a bioaccessible form. Spatial variability of As bioaccesibility in the soils was also recognised throughout the mine site as a function of mineralogy. Multivariate statistical analysis identified a sulphide component responsible for the reduced As bioaccessibility of one cluster of soils. In the larger cluster of acidic mine soils covered by woodland As is mainly hosted in Fe oxyhydroxides whose partial

\footnotetext{
*Address Correspondence to Barbara Palumbo-Roe, British Geological Survey, Keyworth, Nottingham, NG12 5GG, U.K, Tel: 44+115+9363542, Fax: 44+115+9363261, e-mail: bpal@bgs.ac.uk
} 
dissolution is responsible for the bioaccessible As fraction. It was highlighted that the degree of $\mathrm{Fe}$ oxyhydroxide crystallinity might represent an important factor influencing arsenic bioaccessibility. Mine soils from Devon Great Consols Mine showed overall higher As bioaccessibility (15\%) than other mineralised soils not affected by mining activities and background soils within the Tamar Catchment whose percent bioaccessible As median values were $9 \%$.

Keywords: Arsenic, Bioaccessibility, Mine waste, Soil contamination, Devon.

\section{INTRODUCTION}

Mineral exploitation in SW England can be traced back to pre-Roman times with the main period of mining occurring in the mid-nineteenth century. Mining and smelting activities have left a legacy of contaminated land, with As- and Cu-rich mine tailings and other wastes abundant. Today, many of the old mining and smelting sites are derelict contaminated land, with extensive areas of mine spoil and ruins of stacks and arsenic calciners.

A soil geochemical survey of the $920 \mathrm{~km}^{2}$ Tamar catchment in SW England (Fig. 1) undertaken by the British Geological Survey ${ }^{[1]}$ demonstrated that approximately 60\% of the sites throughout the catchment had total soil As values above the Soil Guideline Value (SGV) of $20 \mathrm{mg} \mathrm{kg}^{-1}$ for residential land use. ${ }^{[2]}$ The most contaminated land was in the south of the catchment, in the Kit Hill/Gunnislake and Tamar Valley areas, in areas of intense former mining activity. The tiered risk-based approach advocated in UK guidance for the assessment of contaminated land suggests that further site- 
specific studies should be undertaken for these soils. However, the assumption for the development of generic guideline values for contaminants in soils ${ }^{[2]}$ is that the total As concentration ingested from soils is taken up into the body via the gastro-intestinal tract. As a result of using the total element concentration to asses the human risk and derive the SGVs, if As in soils is not $100 \%$ bioaccessible and less available than the more soluble forms of As dissolved in water, an overestimation of the associated health risk is likely and contaminated sites may be designated unsuitable for their present or intended use.

To assess the fraction of As in the soil that is likely to be bioaccessible, and hence improve estimates of human health risk, soil extraction tests have been developed that mimic the conditions in the human gastrointestinal tract. In this study, a modified version of the physiologically based extraction test (PBET) developed by Ruby et al. ${ }^{[3]}$ and described by Cave et al. ${ }^{[4]}$, was carried out to measure the bioaccessibility of As in soils and mine wastes from Devon Great Consols (DGC) Mine on the east bank of the River Tamar, SW England.

The relationship between As bioaccessibility, As partitioning in the mineral phase and soil properties was investigated. This is important to estimate the medium-long term fate of As and its bioaccessibility in the environment.

\section{MATERIALS AND METHODS}




\section{Study Area and Sample Collection}

The Devon Great Consols Mine on the east bank of the River Tamar in the Tavistock district was one of the most successful Cu producers during SW England's global dominance of the $\mathrm{Cu}$ mining industry in the 1800s. The mine, which was derived from the consolidation of five adjacent mines, worked on lodes mainly consisting of chalcopyrite, pyrite and some arsenopyrite and cassiterite with quartz, fluorspar and brecciated host mudrocks cemented by chlorite or siderite. Later attention turned to As and an output of over 70000 tons was recorded between 1848 and $1909 .{ }^{[5]}$ In the 1870s half the world's As production was estimated to come from half a dozen mines in the Callington and Tavistock area, including Devon Great Consols. Mining activity at Devon Great Consols ended in 1930. Today the highest concentrations of As, $\mathrm{Cu}$, Sn and $\mathrm{W}$ in the Tamar catchment are found around the Devon Great Consols Mine. [1]

One hundred and nine soils and tailings were sampled at Devon Great Consols Mine and in the surroundings of the mine, 87 mine soils and 22 tailings. Further sampling included 20 soils from a site on agricultural land located at Higher Todsworthy Farm, Drakewalls (mineralized soils), containing a mineral lode that has not been worked. Five soils around Bere Alston village (background soils, taken outside of the mineralised area, approximately $7 \mathrm{~km}$ to the south-east of DGC) were also collected. All samples (0-15 cm depth) were made up of a composite of material from auger flights taken from five holes distributed within an area of approximately one metre square. 


\section{Chemical Analysis}

All samples were air-dried and sieved to $<250 \mu \mathrm{m}$. The soil $\mathrm{pH}$ was measured in $0.01 \mathrm{M} \mathrm{CaCl}_{2}$ solution, liquid to solid ratio of 5 to 2 . The organic matter content was estimated by measuring the weight loss after heating to a temperature of $450{ }^{\circ} \mathrm{C}$ for a minimum of 4 hours, i.e. loss on ignition (LOI). Total element content of the $<250 \mu \mathrm{m}$ fraction was obtained by inductively coupled plasma emission spectroscopy (ICPAES) after digestion of the samples ( $0.25 \mathrm{~g})$ with a mixture of concentrated hydrofluoric $(1 \mathrm{~mL})$, perchloric $(0.4 \mathrm{~mL})$ and nitric $(0.8 \mathrm{~mL})$ acids.

\section{Partitioning by Sequential Extraction}

Chemical sequential extraction was carried out in order to characterise element mineral distribution. Two grams of sample were supported on a filtration membrane in a centrifuge tube. Extraction was then carried out using first, for steps 1 and 2, deionised water and then separate aliquots of aqua regia of increasing concentration, that were passed through the sample under centrifugal force. Each extraction step was carried out twice (0.01 M (steps 3 and 4), $0.05 \mathrm{M}$ (steps 5 and 6), $0.1 \mathrm{M}$ (steps 7 and 8), $0.5 \mathrm{M}$ (steps 9 and 10), $1 \mathrm{M}$ (steps 11 and 12), $5 \mathrm{M}$ (steps 13 and 14) aqua regia) and $10 \mathrm{~mL}$ of leaching solution used. For the $0.1,0.5,1$ and $5 \mathrm{M}$ acid extracts, 0.25, 
0.50, 0.75 and $1 \mathrm{~mL}$, respectively, of hydrogen peroxide were also added to each extractant before making up to $10 \mathrm{~mL}$ volume. The solutions obtained were analysed for major and trace elements by ICP-AES. A data-processing algorithm was used to identify the number of physico-chemical components extracted, their composition and the proportion in each extract according to the Chemometric Identification of Substrates and Element Distributions (CISED) method described in Cave et al. ${ }^{[4]}$ The chemometric data-processing is based on the assumption that the material is made up of a mixture of discrete physico-chemical components characterised by a distinct element composition. Under increasing acid concentration each physico-chemical component will dissolve according to its degree and rate of solubility.

The following outputs from processing the CISED soil extraction data are generated: a series of profiles or 'extractograms' for each sample extracted (one for each identified component); a table of the elemental compositions of each identified component, and information relating to the distribution of the elements determined within each identified component. The 'extractograms' show that some physicochemical components present in a soil are extracted at the beginning of the CISED extraction procedure, whereas others require higher acid concentrations depending on their component compositions. 'Extractograms' are simple plots of the total mass of extracted elements against reagent concentration or extraction solution (steps 1-14) and provide useful information on the mobility of the potentially harmful elements within the sample under investigation. Combination of the 'extractogram' with the associated chemical composition data provides a geochemical fingerprint, which helps to identify the source of each component. 


\section{Determination of the Amorphous and Crystalline Iron Oxyhydroxides}

The amorphous Fe oxyhydroxides were extracted using Tamm's reagent $(0.175 \mathrm{M}$ ammonium oxalate $+0.100 \mathrm{M}$ oxalic acid in the dark for 4 hours). The dithionitecitrate method of extraction from Merha and Jackson ${ }^{[6]}$ was used to extract amorphous + crystalline iron oxyhydroxides.

\section{Determination of the Bioaccessible Arsenic}

The bioaccessible As content of the soils was determined using a modified version of the Physiologically Based Extraction Test (PBET) first developed by Ruby et al. ${ }^{[3]}$ to simulate the leaching of a solid matrix in the human gastrointestinal tract and has been fully described by Cave et al. ${ }^{[7]}$ The PBET method simulates the sequential changes in the physico-chemical environment of the gastrointestinal tract, from acidic gastric conditions to neutral to slightly alkaline intestinal conditions. The PBET was divided into three stages, defined by three sets of sampling test solution for analysis. Stage 1 corresponds to the period spent in the stomach environment and stage 2 and 3 those spent in the small intestine environment to different times. One gram of each prepared soil sample was accurately weighed into a wide mouthed HDPE bottle. $100 \mathrm{~mL}$ of simulated gastric solution (1.25 g pepsin, 0.50 g sodium malate, 0.50 g sodium citrate, $420 \mu \mathrm{L}$ lactic acid and $500 \mu \mathrm{L}$ acetic acid made up to $1 \mathrm{~L}$ with freshly prepared de- 
ionised water, adjusted to $\mathrm{pH} 2.5$ with concentrated $\mathrm{HCl}$ ) was added to each bottle. The extraction bottles were placed in an end over end shaker in a thermostat controlled water bath set at $37^{\circ} \mathrm{C}$. After an initial incubation period of one hour at 37 ${ }^{\circ} \mathrm{C}$, a $5.0 \mathrm{~mL}$ aliquot was removed and filtered through a Gelman $0.45 \mu \mathrm{L}$ cellulose filter disk for analysis. This extraction sample is known as the stomach phase. $5.0 \mathrm{~mL}$ of fresh gastric solution was then back-flushed through the used filter into the HDPE bottle. The conditions in each vessel were then altered to simulate the environment found in the small intestine, by titration to $\mathrm{pH} 7.0$ with saturated $\mathrm{NaHCO}_{3}$ and the addition of $175 \mathrm{mg}$ bile salt and $50 \mathrm{mg}$ pancreatin. After incubation in the water bath for a further 2 hours a sample known as small intestine 1 was removed. After an additional 2 hours the final extract was removed, known as small intestine 2 . The value used for calculating As Bioaccessibility is the highest of the bioaccessibility values measured for the stomach, intestine 1 and intestine 2 phases, as this will provide the most conservative value for human health risk assessments.

The fraction of As bioaccessibility was calculated as follows:

$B f \%=\frac{\text { HighestPBETextractedAs }}{\text { TotalAs }} * 100$

\section{Quality Control/Quality Assurance}

The quality control (QC) samples were analysed as part of the ICP-AES and TOC analytical runs to check for instrument drift, accuracy and precision. The QC samples were standard BGS QC solutions made up in accordance with the BGS Quality Assurance/UKAS Quality System. In addition to the routine instrumental analysis of QC samples, the extraction and digestion methods also involved the extraction and 
analysis of blank samples, reference materials (NIST 2710) and analytical and sampling duplicates. The repeatability for the analytical duplicates for the BGS PBET methodology for As was 2-15\%. The repeatability for the sampling duplicates was 1$29 \%$. The uncertainty for total As measurements was $10 \%$ for analytical duplicates and $6-25 \%$ for the sampling duplicates.

\section{RESULTS AND DISCUSSION}

\section{Total Arsenic Concentrations}

Table 1 shows soil pH, LOI, total As, total bioaccessible As, percent bioaccessible As by soil groups and in the tailings. Arsenic concentrations range from $2150 \mathrm{mg} \mathrm{kg}^{-1}$ (median value) in the soils at the mine site to $163 \mathrm{mg} \mathrm{kg}^{-1}$ (median value) in agricultural soils over mineralisation not affected by mining activities. Lower As concentrations are found in the soils collected in Bere Alston, which represents a background area away from mining works (median value of $93 \mathrm{mg} \mathrm{kg}^{-1}$ ). The tailings have an As median value of $19200 \mathrm{mg} \mathrm{kg}^{-1}$.

Figure 2 shows the spatial distribution of As in soils and tailings throughout the mine site. The highest As soil values (up to $69000 \mathrm{mg} \mathrm{kg}^{-1}$ ) occur as clusters around the As works, in proximity to the main tailings heaps (south of the As works) and along the mineral vein passing to the north-west of the mine. The soil concentrations of As in 
the woodland covering a large part of the mine are lower, ranging between 250 and $1000 \mathrm{mg} \mathrm{kg}^{-1}$.

\section{Arsenic Bioaccessibility}

Bioaccessible As shows a median value of $8 \mathrm{mg} \mathrm{kg}^{-1}$ in the background soils of Bere Alston and a median value of $14 \mathrm{mg} \mathrm{kg}^{-1}$ in the mineralised soils not disturbed by mining activities of Drakewalls (Table 1). The bioaccessible As values for the mine tailings and the soils in the mine area and the surroundings are well above any threshold concentrations with median value of $845 \mathrm{mg} \mathrm{kg}^{-1}$ for the tailings and of 351 $\mathrm{mg} \mathrm{kg}^{-1}$ for the soils (Table 1 ).

The trend of dissolution observed in the stomach and intestine phases of the PBET extraction for the studied soils is characterised by higher As solubility passing from the stomach phase $(\mathrm{pH} 2.5)$ to the intestine phase $(\mathrm{pH} 7)$, with the highest PBETextracted As predominantly in the intestine phase of stage 3 (Table 1). The Friedman statistic test (non-parametric two way analysis of variance) was used to establish the significant difference (at 95\% confidence level) across the PBET phases for each soil group.

The percent bioaccessible As (median values) is $15 \%$ for the mine soils, $9 \%$ for both the background soils and the "mineralized" soils and 5\% for the tailings (Table 1), all based upon the bioaccessibility in the intestine phase stage 3. 


\section{Arsenic Partitioning in the Solid Phase}

Sequential extraction data were used to help elucidate the nature of the As hosts in the different soil types and to understand which of these is responsible for the mobile bioaccessible fraction. In order to identify the solid phase partitioning of As the data were subjected to the CISED chemometric data-processing procedure. The chemometric data-processing methodology is based on the assumption that the material is made of a mixture of discrete physico-chemical components characterised by distinct element composition. The extractograms in $\mathrm{mg} \mathrm{kg}^{-1}$ of each component for each extraction stage are reported for two mine soils, DGC 112 and MPS 8, with low and high As concentrations, respectively.

Figure 3 shows the 8 components extracted in soil DGC 112 (mine soil), representing the acid soils ( $\mathrm{pH}_{\mathrm{CaCl} 2}$ in the range of 3-4) from the mine site covered by woodland (Total As= $566 \mathrm{mg} \mathrm{kg}^{-1}$; bioaccessible As= $92 \mathrm{mg} \mathrm{kg}^{-1}$; percent bioaccessible As= $16 \%)$. Each component was named using a combination of the chemical elements that contribute more than $10 \%$ by weight to the composition of the components. It is possible to recognise in the first component extracted at stage 1-2 the composition of an acid soil solution rich in $\mathrm{S}, \mathrm{Al}$ and $\mathrm{K}, \mathrm{Na}$ and $\mathrm{Mn}$. In order of increasing difficulty of extraction two Mn-oxyhydroxide components and a number of $\mathrm{Al}$, $\mathrm{Al}-\mathrm{Fe}$ and $\mathrm{Fe}$ oxyhydroxide components follow. The majority of the As is associated with Fe 
oxyhydroxides and Al- Fe oxyhydroxides mainly extracted at steps 9-14 of the sequential extraction (Fig. 3 and Fig. 5).

The results of the CISED processing of soil MPS 8, a highly contaminated soil (total As= $31000 \mathrm{mg} \mathrm{kg}^{-1}$; bioaccessible As= $1770 \mathrm{mg} \mathrm{kg}^{-1}$; percent bioaccessible As= 5.7 \%) collected in the proximity of the mine calciner (mine soil), show that As is mainly associated with Fe-dominated components extracted at the last stages of the extraction (Fig. 4 and Fig. 5). A subordinate, but significant amount of As is present in a Ca-Fe dominated component. The As-Ca-Fe association were also recognized by scanning electron microscope (SEM) observation in the coatings rimming sulphide grains and

in discrete Ca-As-Fe particles from the mine waste. ${ }^{[8]}$ They undoubtedly formed as a result of ore processing. ${ }^{[9]}$ This Ca-Fe component containing ca $2300 \mathrm{mg} \mathrm{kg}^{-1}$ As shows a peak of extraction at an early stage in the leaching, suggesting higher solubility than the Fe dominated components (Fig. 3), and possibly a greater contribution to the As bioaccessible fraction than the Fe oxyhydroxides.

\section{Spatial Distribution of Bioaccessible Arsenic in the Mine Soils and Relationship with Other Physico-chemical Soil Parameters}

Total concentrations of As and the percent bioaccessible fraction show a large spread of values in DGC mine soils suggesting that the data are derived from more than one population of samples. Deposition of stack emissions during smelting of the sulphide 
ore, wind and water dispersion from tailings heaps, distribution during transport from the shafts and smelters could also have contributed to the As concentrations in the studied mine soils. By using k-means clustering of the soil physico-chemical variables the soils were grouped into 4 clusters, whose spatial distribution throughout the mine is shown in Figure 6.

Figure 7 shows the calculated centroids of each observation cluster. Clusters 1 represents most of the acid soils in the mine covered by woodland and characterised by relatively low As concentrations (total As median value $=1070 \mathrm{mg} \mathrm{kg}^{-1}$ ) and the highest bioaccessible As fraction (percent As bioaccessibility median value $=22 \%$ ). Cluster 2 groups the soils mainly from the eastern part of the mine along the railway tracks used to transport the ore from the shafts, characterised by relatively low As concentrations (total As median value $=843 \mathrm{mg} \mathrm{kg}^{-1}$ ), similar to cluster 1 , but with a lower bioaccessible As fraction (percent As bioaccessibility median value = $10 \%$ ) and higher $\mathrm{K}, \mathrm{Al}, \mathrm{Cr}, \mathrm{V}$ than cluster 1 . Cluster 3 contains a small group of soils predominantly from the north-western mine area corresponding to the mineralised veins and shafts, with higher As concentrations (total As median value $=11000 \mathrm{mg}$ $\mathrm{kg}^{-1}$ ) than cluster 1 and cluster 2 and a percent As bioaccessibility median value of 15 \%. Cluster 4 groups the soils from the area inside the As works and it is characterised by very high concentrations of As (total As median value $=30200 \mathrm{mg} \mathrm{kg}^{-1}$ and up to $69000 \mathrm{mg} \mathrm{kg}^{-1}$ ), Fe and S and the lowest As bioaccessible fraction (percent As bioaccessibility median value $=4.2 \%$ ).

Multiple Linear Regression (MLR) models were produced for cluster 1 and cluster 2, whose percent As bioaccessibility differs while As total content is similar. The total 
element concentration, $\mathrm{pH}$ and organic matter of each sample were used as the explanatory variables and bioaccessible As the response variable. A forward stepwise procedure ${ }^{[10]}$ was used to assess which explanatory variables had a statistically significant effect on the regression and hence would be included in the final model. The two models' coefficients and related statistics are summarised in Table 2 and Table 3 . For cluster 1, the total As content was the only explanatory variable giving a significant $(\mathrm{p}<0.001)$ coefficient describing $93 \%$ of the variance in the bioaccessible As. This suggests that As is mainly bound to one phase whose partial dissolution is responsible for the bioaccessible content. From the results of the sequential extraction (sample DGC 112) it was possible to identify this phase as Fe oxyhydroxides adsorbing or coprecipitating As. The negative intercept in the model suggests that it is only valid over the range of total As in these samples and that there is some nonlinearity as lower total As values are approached. For cluster 2 (Table 3), total As and total S are found to be the only explanatory variables with significant $(\mathrm{p}<0.001)$ coefficients describing $96 \%$ of the variance in the bioaccessible As. This might suggest that there is a portion of As bound to $S$ in a non-bioaccessible form, probably as arsenopyrite (FeAsS), where one would expect the As to be less freely available and locked up in the crystal structure. Arsenopyrite, the primary ore mineral was brought to the arsenic works from the various working mines as well as waste dumps by the railway line and along which soils from cluster 2 group. The suggested presence of at least two different sources of As, an Fe oxyhydroxide source for cluster 1 and an Fe sulphide contribution for cluster 2, might explain the observed difference in bioaccessibility in the two groups of soils and the spatial variability. This is in agreement with Ruby et al. ${ }^{[11]}$ who found that for constant soil particle size As in 
sulphides has lower bioaccessibility than the As bound to Fe and manganese oxyhydroxides.

\section{Fe Oxyhydroxide Crystallinity and Arsenic Bioaccessibility}

An overall higher bioaccessibility of As is shown by the mine soils (median percent bioaccessibility $=15 \%$ ) compared to the mineralised and background soils where As derives from the natural weathering of the parent material in Bere Alston and Drakewells (percent bioaccessibility $<10 \%$ ). The latter values are similar to the values reported for naturally As enriched soils developed on the ironstones from North Lincolnshire and Northamptonshire, UK. ${ }^{[12,13]}$ In all cases the importance of the Fe oxyhydroxides phases in hosting As in these soils was evidenced by the sequential chemical extraction data. As part of investigating the relationship between As and Fe oxyhydroxides, a comparative trial study was carried out on a few soil

samples from the Devon mine site and the Northampton soils on ironstones. ${ }^{[14]}$ Figure 8 shows how the soils from Northampton with a lower percent bioaccessible As $(<10 \%)$ contain Fe oxyhydroxides with a relatively higher degree of crystallinity compared to the Devon Mine soils. The degree of Fe oxyhydroxide crystallinity may affect the mineral dissolution rates and the bioaccessibility of As adsorbed/coprecipitated with the oxyhydroxides. However, the complexity of Fe oxyhydroxides phases and factors affecting As coprecipitation/adsorption processes necessitates that further studies are undertaken to better understand the influence of various soil physical and chemical properties on As bioaccessibility. 
Insights into the Solution Chemistry of PBET-extracts Applied to the Mine Soils from Devon

The PBET method simulates the sequential changes in the physico-chemical environment of the gastrointestinal tract, from acidic gastric conditions to neutral to slightly alkaline intestinal conditions. In the literature there is no agreement on the benefit of carrying out the extraction test under aerobic/anaerobic conditions. The present modified version of the PBET test has been carried out in screw-top polypropylene vessels, in aerobic conditions. Measurements of the redox condition of the extraction fluids in the PBET test indicate Eh values of around $500 \mathrm{mV}$ without major changes from the stomach to the intestine phase.

Mobility of As in natural waters and soil solutions depends primarily on the role of mechanisms such as adsorption and coprecipitation on Fe oxyhydroxides. ${ }^{[15]}$ Arsenic adsorption on Fe oxyhydroxides is $\mathrm{pH}$ dependent with $\mathrm{As}(\mathrm{V})$ sorption decreasing at alkaline pH. ${ }^{[16]}$ Under reducing conditions Fe would be in a soluble ferrous state and As present as As(III), which is less strongly adsorbed on Fe oxyhydroxides than As(V). Under these conditions one would expect As to be highly soluble. Overall, the described mechanisms will apply to the gastrointestinal system, but be complicated by the presence of other major anions such as phosphates and organic chelants, which may be as important as Fe oxyhydroxides in the mechanisms of sorption/ displacement/ release. 
The stability phase diagram for $\mathrm{Fe}$ at $37^{\circ} \mathrm{C}$ shows that soluble $\mathrm{Fe}(\mathrm{II})$ is the stable $\mathrm{Fe}$ species in the stomach phase (Fig. 9). Due to the low $\mathrm{pH}, \mathrm{Fe}(\mathrm{II})$ is stable over a wide Eh range and low Eh values are not so critical to ensure Fe reduction. According to the same stability diagram a shift in $\mathrm{pH}$ towards the alkaline values of the intestine phase could cause colloidal ferric Fe oxyhydroxides to form and precipitate, with consequent decrease of Fe and coprecipitated As from solution. However, the trend of dissolution observed in the stomach and intestine phases for the studied soils is characterised by an increase in As and Fe solubility passing from the stomach phase to the intestine phase.

Consideration of only the inorganic composition of the fluid is not sufficient to explain the Fe in solution at the alkaline $\mathrm{pH}$ of the intestine phase. A closer look at the fluid composition shows the presence of important organic chelants for Fe such as sodium citrate and malic acid, known to improve the absorption of Fe from food, which might enhance the extent of Fe dissolution. In addition, in the intestine fluid bile salts and pancreatin are added. These are characterised by the presence of phosphorous. Arsenate release as a result of ligand-exchange reactions of arsenate with phosphate ions could also represent an important mechanism. ${ }^{[17-19]}$.

\section{CONCLUSIONS}

Mine soils from Devon Great Consols Mine exhibited higher As bioaccessibility than the soils not affected by mining activities and background soils within the Tamar catchment. 
The sequential extraction data showed that As is mainly bound to Fe oxyhydroxides for most of the soils. Multivariate statistical analysis indicated the presence of at least two mineralogical phases (Fe oxyhydroxides and $\mathrm{Fe}$ sulphides) to affect the bioaccessibility of As in these soils. Preliminary results on $\mathrm{Fe}$ oxyhydroxide crystallinity suggested that the degree of Fe oxyhydroxide crystallinity influences dissolution rate and As bioaccessibility.

The solution chemistry of the PBET extracts was studied and the increasing trend of dissolution of both As and $\mathrm{Fe}$ at increasing $\mathrm{pH}$ from the stomach to the intestine phase suggested the major role of organic chelants during the PBET extraction of As.

\section{ACKNOWLEDGEMENTS}

This study is published with the permission of the Director, British Geological Survey (NERC). Gratefully acknowledgements are due to Mr M. Snelgrove, Tavistoch Woodland manager, for allowing access to Devon Great Consols Mine. Maps in this paper are based upon British Geological Survey (BGS) maps, and the Ordnance Survey topographic maps are reproduced with the permission of The Controller of Her Majesty's Stationery Office, (C) Crown Copyright. All rights reserved. Licence Number 100017897/2007.

\section{REFERENCES}


1. Rawlins, B.G.; O'Donnel, K; Ingham, M. Geochemical survey of the Tamar catchment (south-west England). British Geological Survey Report, CR/03/027; 2003; pp 232.

2. DEFRA and EA. Soil guideline values for arsenic contamination. R\&D Publication SGV 1, Environment Agency, Bristol, 2002.

3. Ruby, M.V.; Davis, A.; Schoof, R.; Eberle, S; Sellstone, C.M. Estimation of lead and arsenic bioavailability using a physiologically based extraction test. Environ Sci Technol 1996, 30(2), 422-430.

4. Cave, M.R; Milodowski, A.E.; Friel, H. Evaluation of a method for Identification of Host Physico-chemical Phases for Trace Metals and Measurement of their Solid-Phase Partitioning in Soil Samples by Nitric Acid Extraction and Chemometric Mixture Resolution. Geochemistry: Exploration, Environment, Analysis 2004, 4, 71-86.

5. Dines, H.G. The Metalliferous Mining Region of South-West England. Memoirs of the Geological Survey of Great Britain. HMSO, London, 1956; 795 pp.

6. Merha, O.P, Jackson, M.L. Iron oxide from soils and clays by dithionitecitrate system buffered with sodium bicarbonate. In Proc. $7^{\text {th }}$ International Conference on Clays and Clay Minerals, 1960; 317-327.

7. Cave, M.R.; Wragg, J.; Palumbo, B; Klinck, B.A. Measurement of the Bioaccessibility of Arsenic in UK soils. P5-062/TR1, Environment Agency, 2003.

8. Klinck, B. A.; Palumbo, B.; Cave, M.R.; Wragg, J. Arsenic dispersal and bioaccessibility in mine contaminated soils: a case study from an abandoned 
arsenic mine in Devon, UK. British Geological Survey Report, Keyworth, Nottingham, 2005; pp. 52.

9. Palumbo-Roe, B; Klinck, B; Cave, M. Arsenic speciation and mobility in mine wastes from a copper-arsenic mine in Devon, UK: an SEM, XAS, sequential chemical extraction study. Trace Metals and other Contaminants in the Environment, 2007, 9, 431-460.

10. Draper, N.; Smith, H. Applied Regression Analysis, Wiley, $3^{\text {rd }}$ Edition, 1998.

11. Ruby, M. V.; Schoof, R.; Brattin, W.; Goldade, M.; Post, G.; Harnois, M.; Mosby, D. E.; Casteel, S. W.; Berti, W.; Carpenter, M.; Edwards, D.; Cragin, D.; Chappell, W. Advances in evaluating the oral bioavailability of inorganics in soil for use in human health risk assessment. Environ Sci Technol, 1999, 33, 3697-3705.

12. Palumbo-Roe, B.; Cave, M. R.; Klinck, B. A.; Wragg, J.; Taylor, H.; O'Donnell, K. E.; Shaw, R. A. Bioaccessibility of arsenic in soils developed over Jurassic ironstones in eastern England. Environmental Geochemistry and Health, 2005, 27, 121-130.

13. Wragg, J. A study of the relationship between arsenic bioaccessibility and its solid phase distribution in Wellingborough soils. $\mathrm{PhD}$ thesis; University of Nottingham, UK, 2005; 303 pp.

14. Wiship, P.D. An investigation of soils, the distribution of Fe oxides and their relationship to arsenic content. M.Sc. thesis; Loughborough University, UK, 2002; 31 pp.

15. Smedley, P.L.; Kinniburgh, D.G. A review of the source, behaviour and distribution of arsenic in natural waters. Applied Geochemistry, 2002, 17(5), 517-568. 
16. Pierce, M.L., Moore, C.B. Adsorption of arsenite and arsenate on amorphous Fe hydroxide. Water Research, 1982, 16, 1247-1253.

17. Jackson, B.P.; Miller, W.P. Effectiveness of Phosphate and Hydroxide for Desorption of Arsenic and Selenium Species from Fe Oxides. Soil Sci Soc Am J, 2000, 64(5), 1616-1622.

18. Violante, A.; Pigna, M. Competitive Sorption of Arsenate and Phosphate on Different Clay Minerals and Soils. Soil Sci Soc Am J, 2002, 66(6), 1788-1796.

19. Zhao, H.; Stanforth, R. Competitive Adsorption of Phosphate and Arsenate on Goethite. Environ Science Technology, 2001, 35, 4753-4757.

\section{FIGURE CAPTIONS}

Figure 1. Map of interpolated arsenic concentrations in the Tamar catchment based on 468 soil samples, source (Rawlins et al. ${ }^{[1]}$ ) on 468 soil samples, source (Rawlins et al. ${ }^{[1]}$ ), and location of the Great Consols (DGC) Mine.

Figure 2. Spatial distribution of As concentrations in topsoils and mine tailings of DGC mine.

Figure 3. Extractogram of the 8 CISED components extracted in soil DGC 112.

Figure 4. Extractogram of the 8 CISED components extracted in soil MPS 8. 
Figure 5. Distribution of As amongst the CISED components of soil DGC 112 and MPS 8.

Figure 6. Map showing the spatial distribution of the clusters of soils identified by kmean clustering.

Figure 7. Calculated centroids for the physico-chemical variables around which each observation clusters.

Figure 8. Percent bioaccessible As vs $\mathrm{Fe}_{\text {amorphous }}\left(\mathrm{Fe}_{\text {amorphous }}+\mathrm{Fe}_{\text {crystalline }}\right)$.

Figure 9. Eh-pH diagram showing fields of stability for dissolved Fe. Activity of Fe is $10^{-5} \mathrm{M}(5 \mathrm{mg} / \mathrm{l}), \mathrm{T} 37^{\circ} \mathrm{C}, \mathrm{P} 1 \mathrm{~atm}$. 
Table 1 - Statistics of Total As, Bioaccessible As, Percent Bioaccessible As, soil pH and LOI for DGC mine soils, mineralised soils, background soils and tailings.

\begin{tabular}{|c|c|c|c|c|c|}
\hline \multirow{4}{*}{$\begin{array}{l}\text { Total As } \\
\text { mgkg }^{-1}\end{array}$} & & $\begin{array}{c}\text { Mine soils } \\
\mathrm{N}=87\end{array}$ & $\begin{array}{l}\text { Mineralised soils } \\
\qquad \mathrm{N}=20\end{array}$ & $\begin{array}{l}\text { Background soils } \\
\qquad \mathrm{N}=5\end{array}$ & $\begin{array}{c}\text { Tailings } \\
\mathrm{N}=22\end{array}$ \\
\hline & Mean & 6900 & 166 & 105 & 31700 \\
\hline & Range & 249-68900 & 123-205 & $59-172$ & $1280-204500$ \\
\hline & Median & 2150 & 163 & 93 & 19170 \\
\hline
\end{tabular}

Total Bioaccessible As

$\begin{array}{ll}\text { mgkg }^{-1} & \text { Mean } \\ & \text { Range }\end{array}$

Median

705
$12-2740$
363

363

16
$11-27$
14

14

Bioaccessible As Stomach phase

$\begin{array}{ll}\text { mgkg }^{-1} & \text { Mean } \\ & \text { Range }\end{array}$

$$
\text { Median }
$$

290

$5-1280$

125

7
$5-12$
6

Bioaccessible As Intestine 1 phase

$$
\begin{array}{ll}
\text { mgkg }^{-1} & \text { Mean } \\
& \text { Range }
\end{array}
$$

$12-2650$

Median

Bioaccessible As Intestine 2 phase

$$
\begin{array}{ll}
\text { mgkg }^{-1} & \text { Mean } \\
& \text { Range } \\
& \text { Median }
\end{array}
$$

703

$12-2740$

351

15
$11-24$
15

9

1654

7-13

9

58-10870

740

26-5200

419

769

9


Table 2 - Multiple linear regression parameters for the Cluster 1.

Regression parameters and corresponding statistics:

Determination coefficient $r^{2}: 0.933$

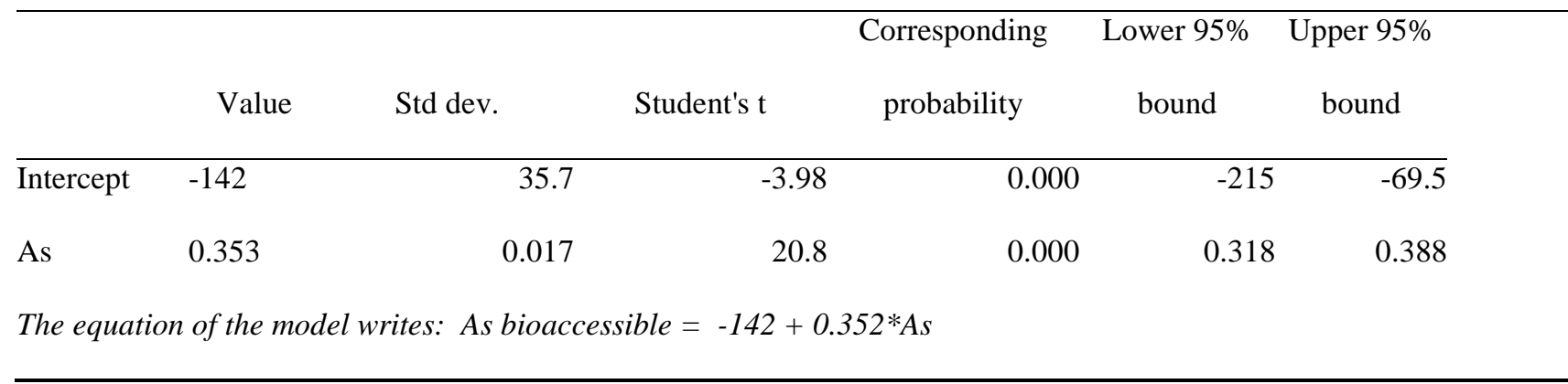


Table 3 -Multiple linear regression parameters for the Cluster 2.

Regression parameters and corresponding statistics:

Determination coefficient $\mathrm{r}^{2}: 0.961$

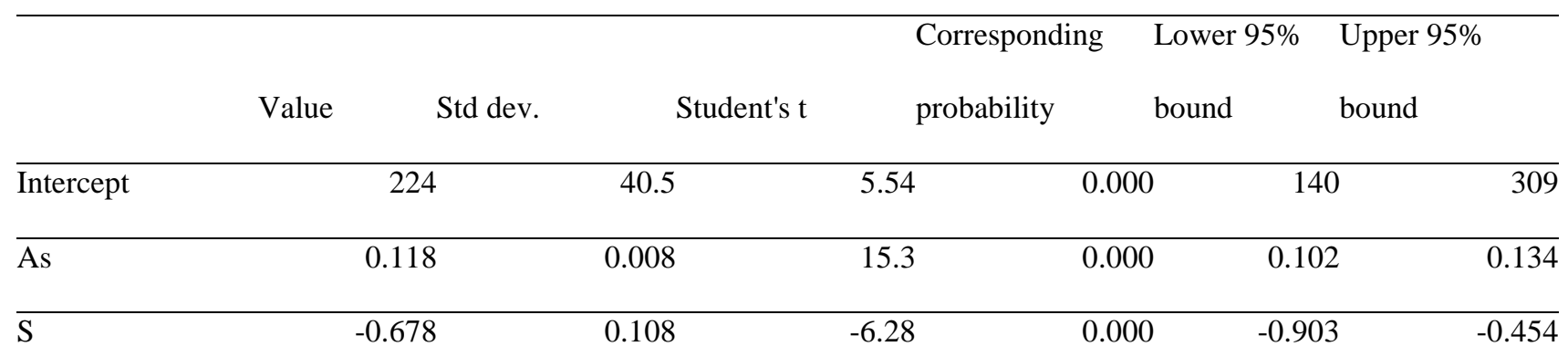

The equation of the model is: As bioaccessible $=224+0.118 *$ As $-0.678 * \mathrm{~S}$ 
FIGURE 1
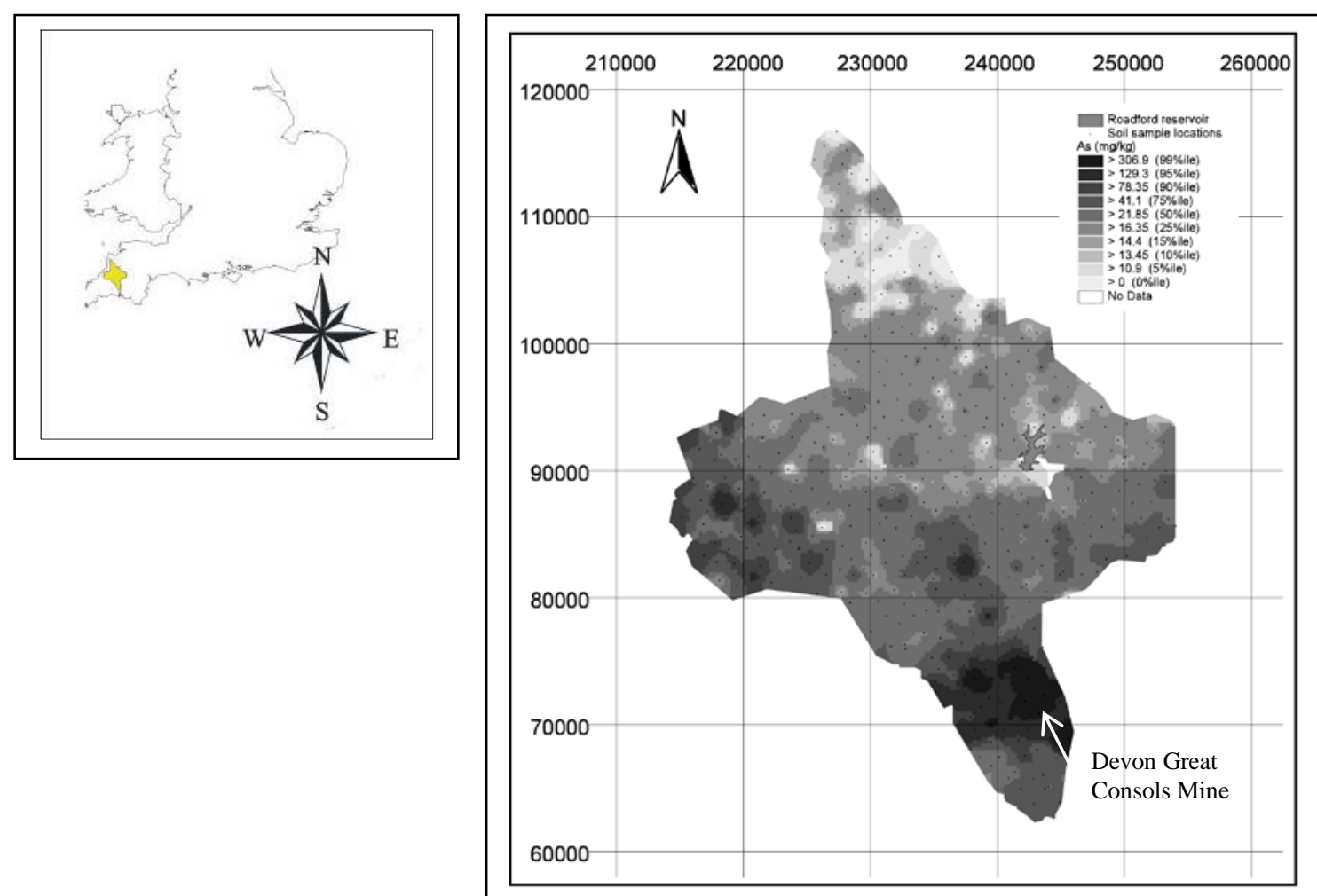
FIGURE 2

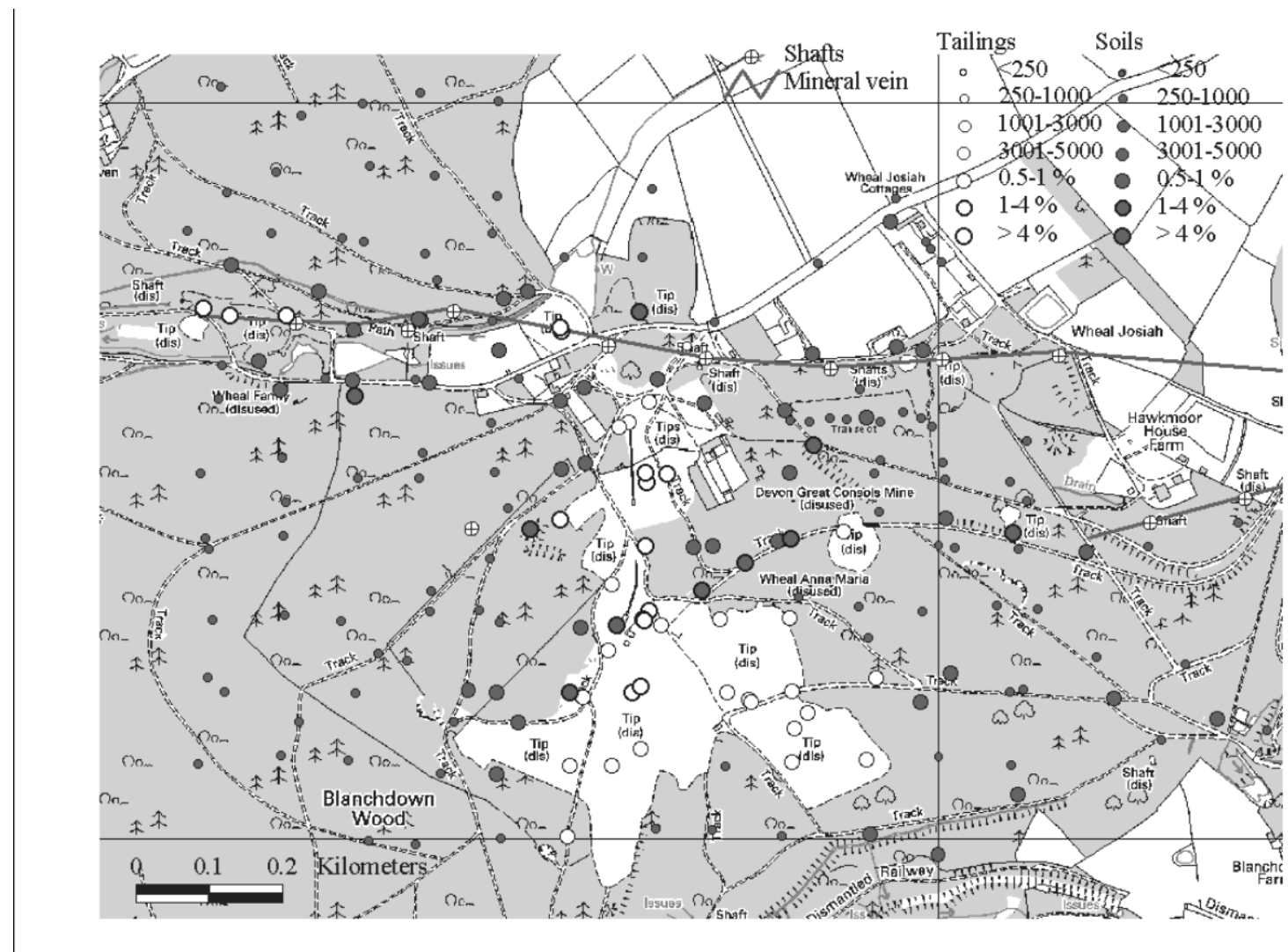

Topography @ Crown Copyright. All rights reserved 
FIGURE 3

\section{DGC 112}
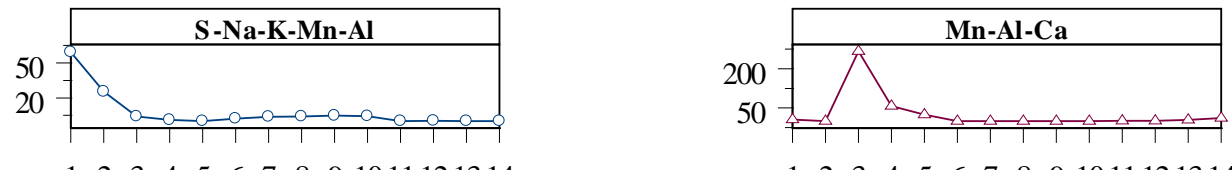

$\begin{array}{llllllllll}1 & 2 & 3 & 4 & 5 & 6 & 7 & 8 & 9 & 1011121314\end{array}$

12345667891011121314
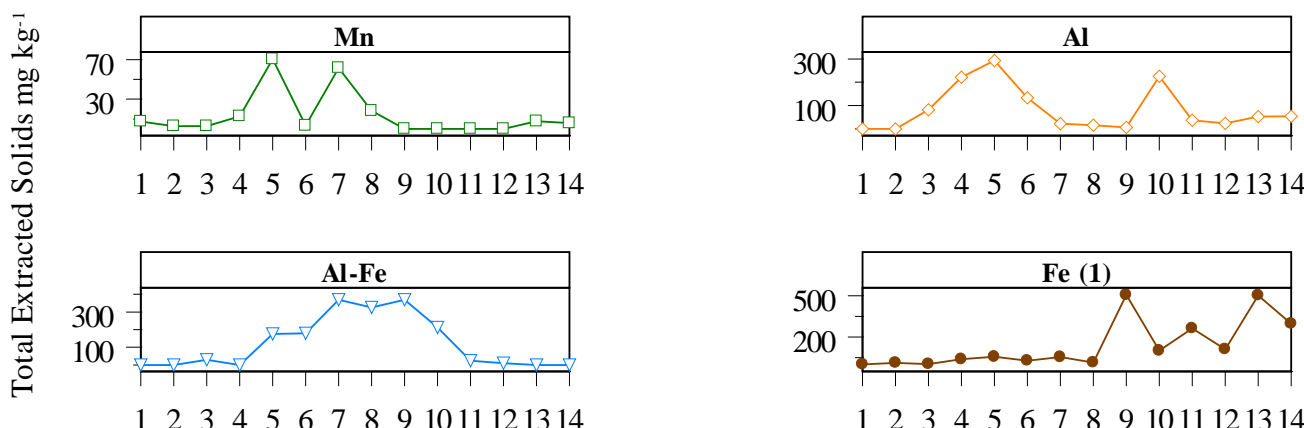

12345677891011121314

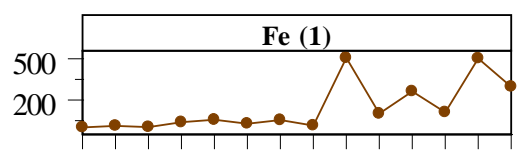

1234567891011121314
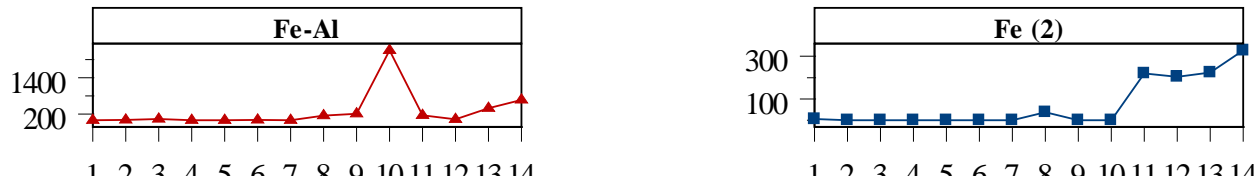

Extraction Number 
FIGURE 4

MPS 8
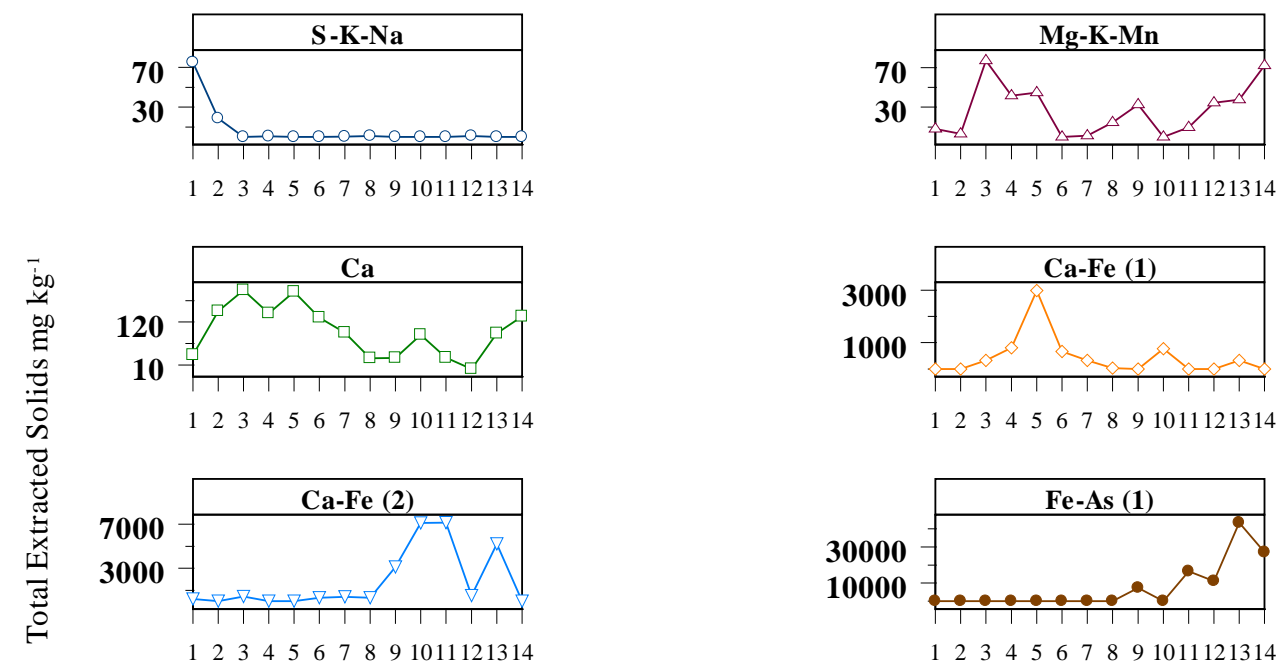

122345678991011121314
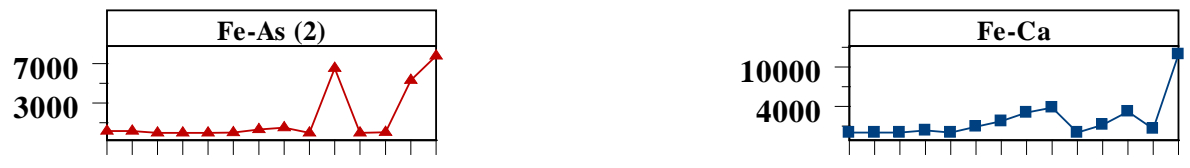

1234567891011121314

12234567891011121314

Extraction Number 
FIGURE 5
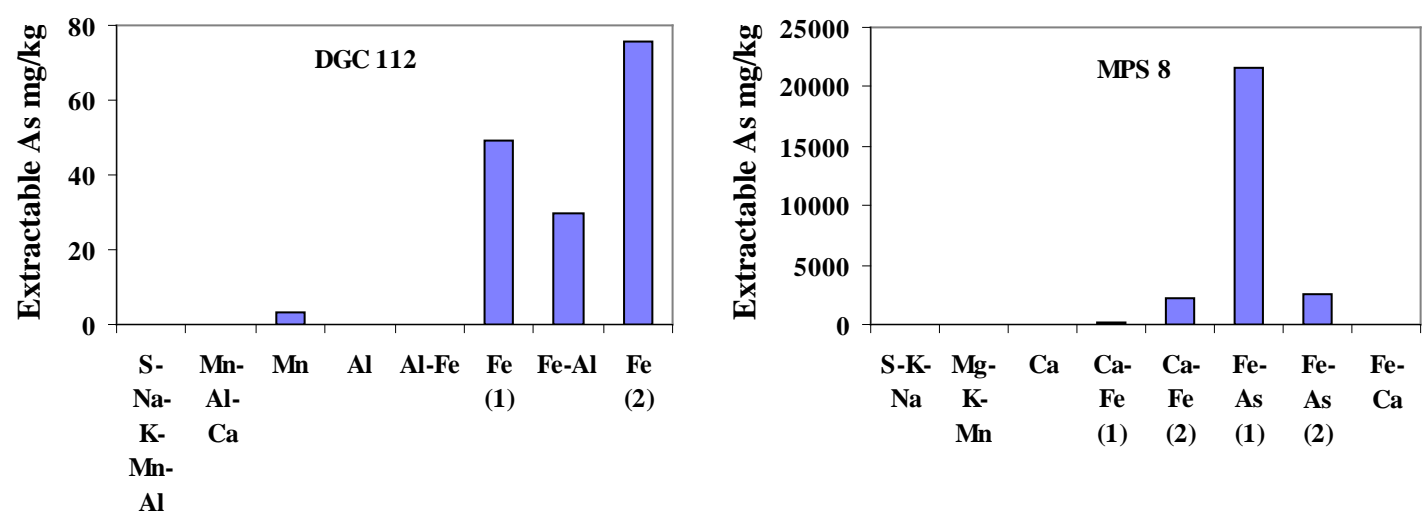

Al 
Figure 6

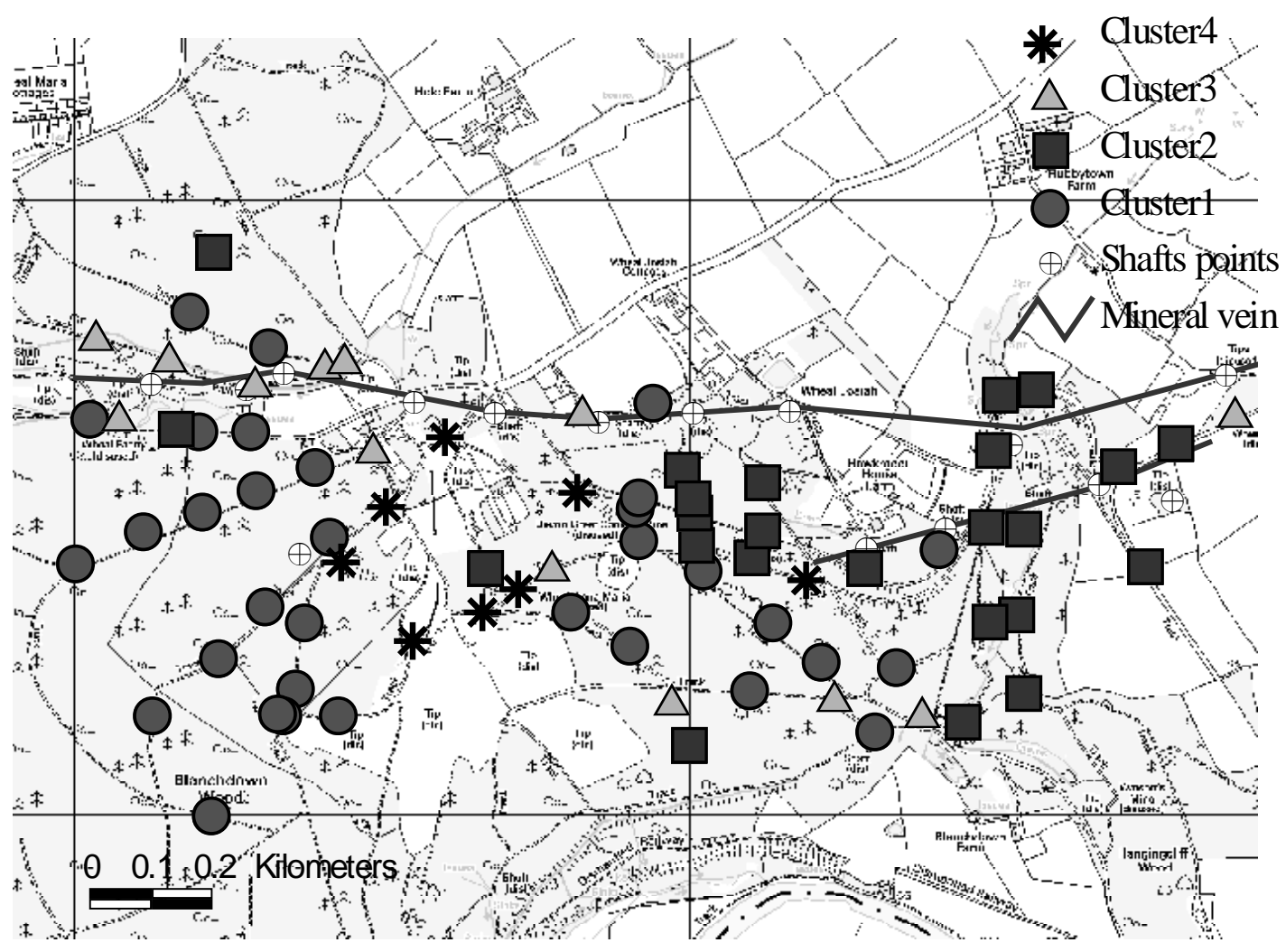

Topography (C) Crown Copyright. All rights reserved 
FIGURE 7

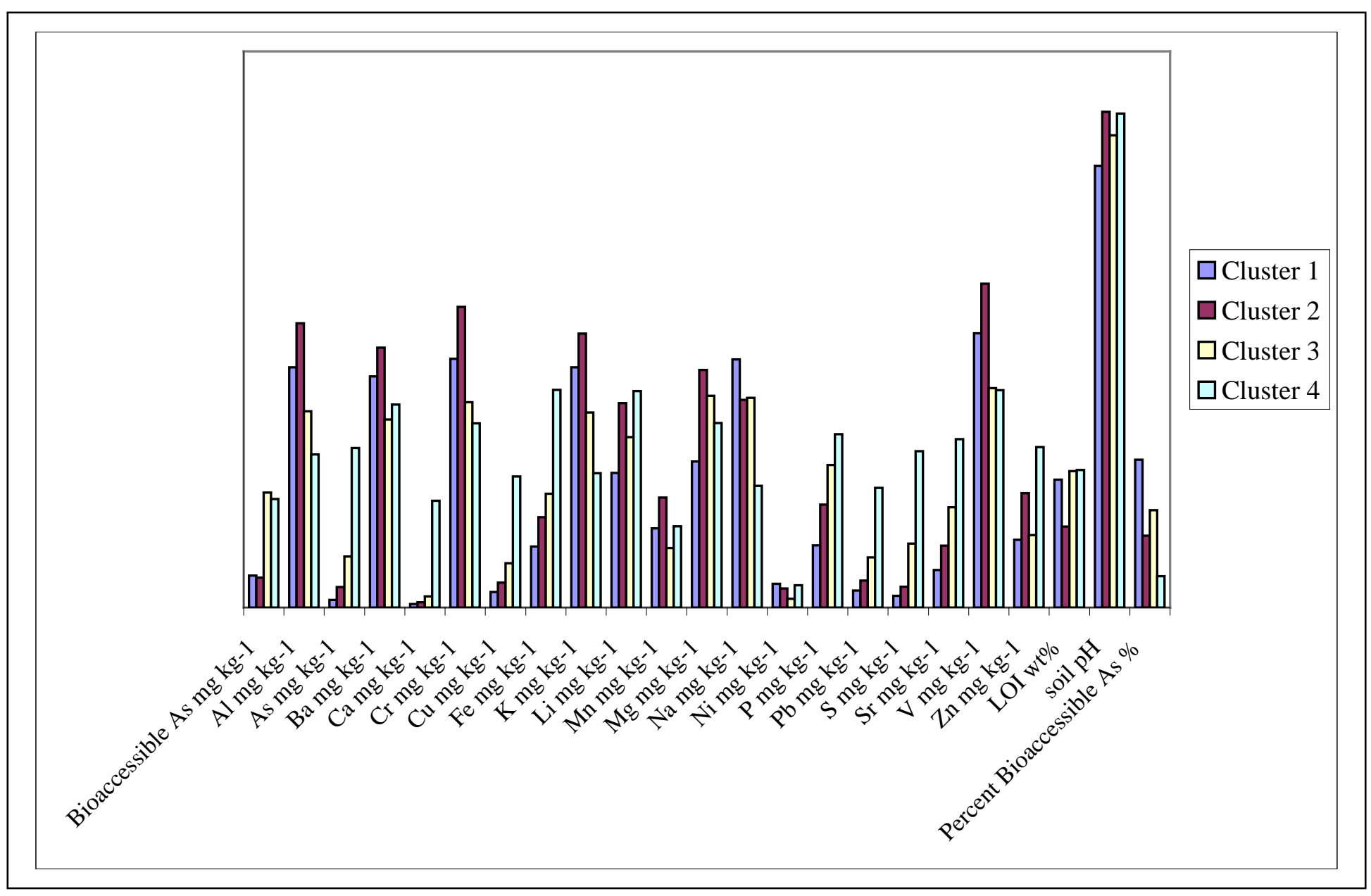


Figure 8

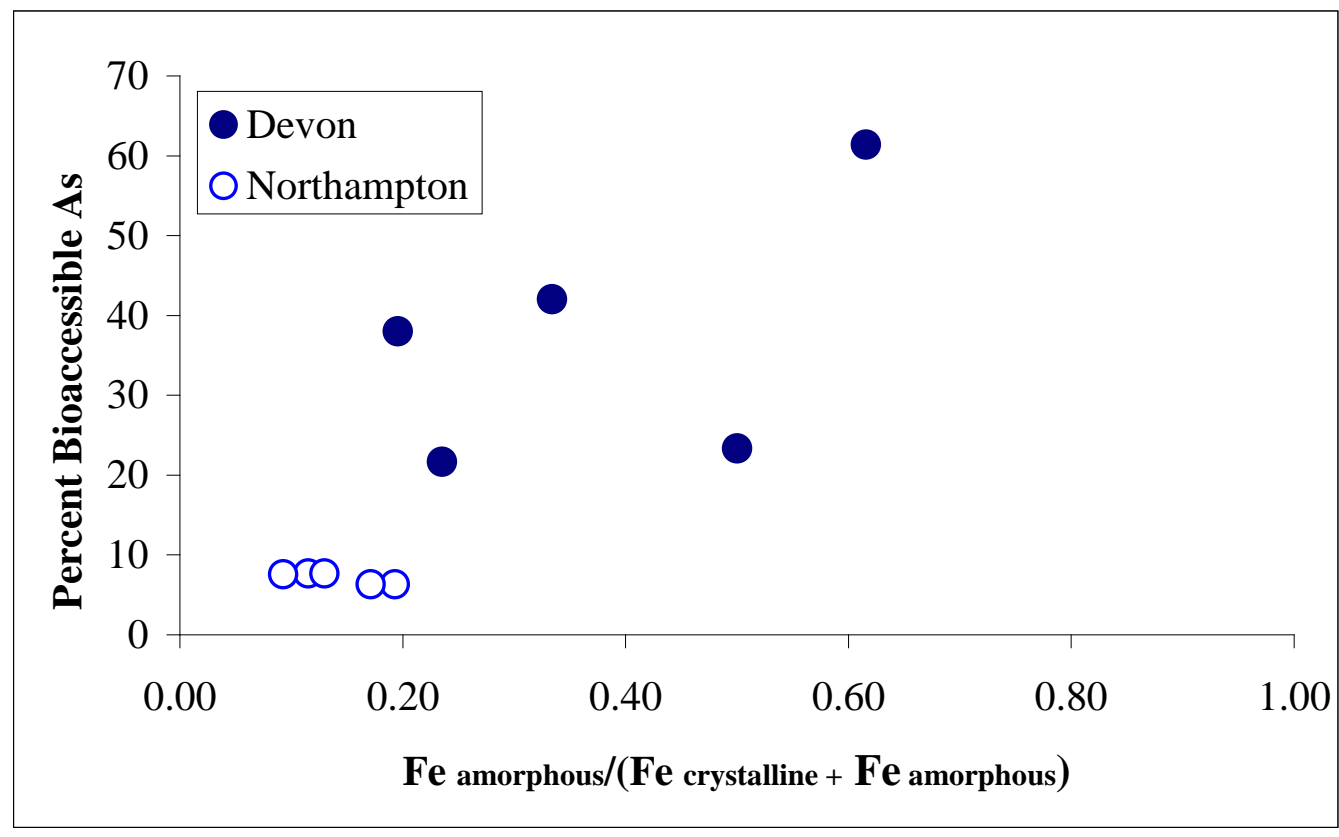




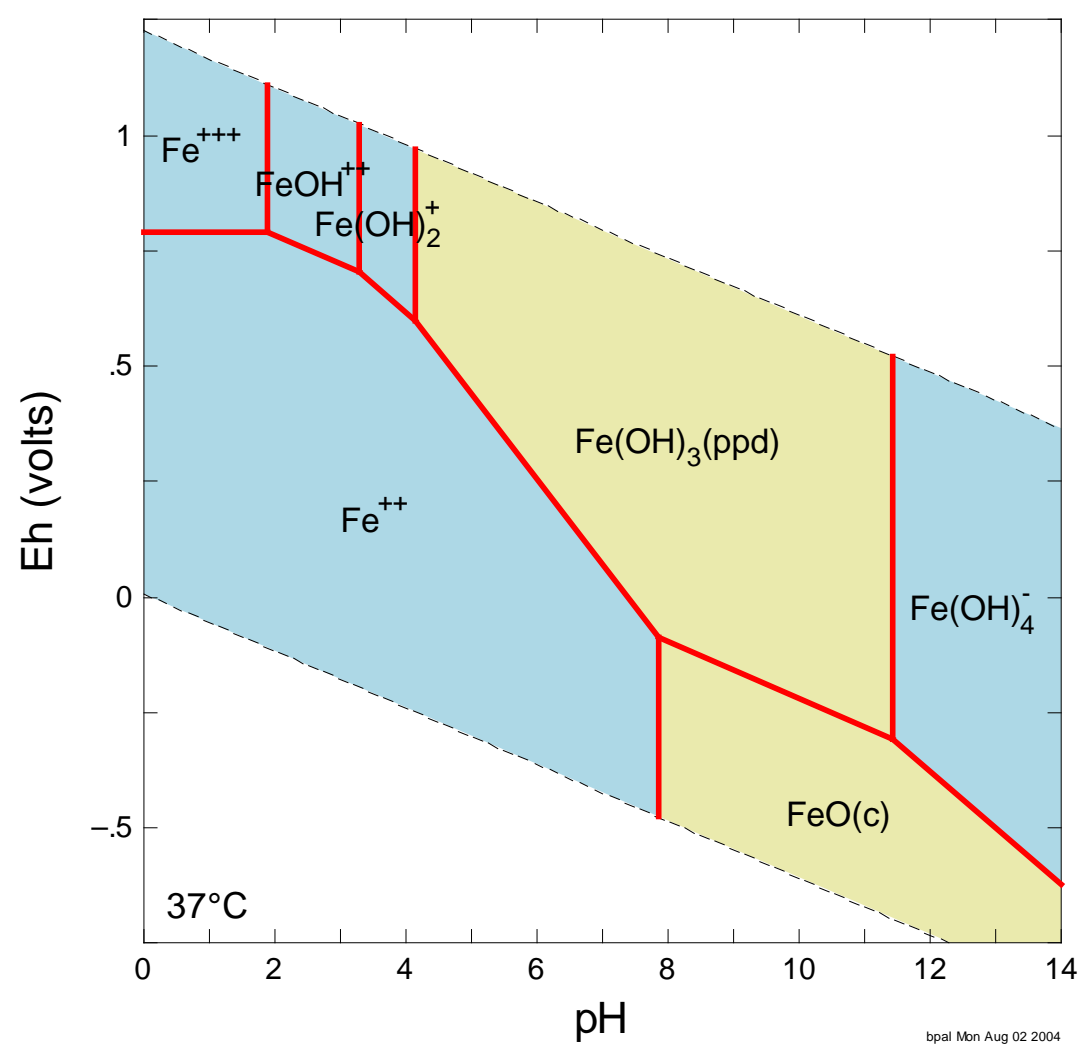

Figure 9 
